\title{
INDICADORES PADRÃO DE EFICIÊNCIA DAS COOPERATIVAS DE CRÉDITO DE MINAS GERAIS POR MEIO DA ANÁLISE ENVOLTÓRIA DE DADOS (DEA)
}

\author{
Standard Indicators of the Efficiency of Minas Gerais Credit Cooperatives Obtained from Data \\ Envolvement Analysis (DEA)
}

\begin{abstract}
RESUMO
Este trabalho traz como contribuição a construção de indicadores de referência para a análise da eficiência das cooperativas de crédito, utilizando a Análise Envoltória de Dados (DEA). A eficiência de uma cooperativa de crédito pode ser medida pela sua capacidade de oferecer crédito a seus cooperados, uma vez que um dos propósitos de sua constituição é democratizar o acesso ao crédito, tornando-o mais barato e acessível. Além disso, a eficiência da cooperativa também pode ser medida pela sua capacidade de gerar sobras, as quais em parte são distribuídas, incrementando a renda do associado ou reinvestidas, promovendo o crescimento da instituição. Dessa forma, este trabalho objetivou analisar a eficiência das cooperativas de crédito de Minas Gerais, de acordo com o porte, bem como identificar indicadores de padrão de eficiência. O período analisado foi de 2013 a 2015. Os resultados obtidos por meio da fronteira normalizada indicaram que as cooperativas de pequeno, médio e grande porte mais eficientes tem despesas administrativas e de captação que representam 4,04\%, 5,52\% e 6,82\%, respectivamente, da soma dos outputs analisados (sobras + operações de crédito). Estes valores podem ser utilizados como parâmetros para a análise dessas instituições, de forma a avaliar a gestão interna dos recursos na cooperativa e o quanto isso tem se traduzido em resultados para os cooperados.
\end{abstract}

Rodrigo Moreira Braz

Universidade Federal de Viçosa

rodrigo.m.braz@outlook.com

Rosiane Maria Lima Gonçalves

Universidade Federal de Viçosa

rosiane.goncalves@ufv.br

Recebido em: 06/11/2017. Aprovado em: 20/02/2020.

Avaliado pelo sistema double blind review

Avaliador científico: Elisa Reis Guimarães

\begin{abstract}
The contribution of the present work is the construction of reference indicators for the analysis of the efficiency of credit cooperatives through the use of Data Envelopment Analysis (DEA). The efficiency of a credit union can be measured by its ability to offer credit to its members, since one of its purposes is to make credit available to all people by making it cheaper and easier to obtain. In addition, the efficiency of a cooperative can also be measured by its ability to generate surplus, which is partly distributed, thus increasing the income of its members, or reinvested, thus promoting the growth of the institution. Therefore, the present study aimed to analyze the efficiency of credit cooperatives in Minas Gerais, according to their size, and identify indicators of efficiency standard. The analysis was conducted from 2013 to 2015 . The results obtained through the normalized frontier indicated that the most efficient small, medium and large cooperatives have administrative and fund-raising expenses that represent $4.04 \%$, 5.52\% and $6,82 \%$, respectively, of the sum of the outputs analyzed (surplus + credit operations). These values can be used as parameters for the analysis of these institutions, aiming to assess the internal management of the resources in the cooperative and the amount of benefits provided to their members.
\end{abstract}

Palavras chave: Instituições Financeiras. Crédito Cooperativo. Desempenho.

Keywords: Financial Institution. Cooperative Credit. Performance.

\section{INTRODUÇÃO}

Diversos fatores no dinamismo atual da economia abrem espaço para inserção de confiabilidade, menor custo e exclusividade em questões de capitação e disposição de crédito. As instituições financeiras convencionais atendem ao público em geral, com uma grande amplitude de clientes e pouco ou nenhum contato pessoal com os mesmos. Assim, a análise do crédito fica condicionada às comprovações que o cliente apresentar e a consulta ao cadastro de inadimplentes, o que dificulta o controle da inadimplência e faz, dentre outros fatores, com que os juros e os meios para se custear sem prejuízos suas operações sejam elevados.

Nesse contexto, vem se destacando ao longo dos anos as Cooperativas de Crédito, que têm como característica o atendimento de um público específico, seus 
associados, com um custo de disposição e captação de crédito diferenciado e com um relacionamento pessoal pouco evidenciado pelas instituições bancárias convencionais.

As cooperativas de crédito são instituições financeiras que desempenham a mesma função das instituições convencionais, porém com um cunho social, promovendo o desenvolvimento de seus associados e disponibilizando crédito com um custo menor (SCHARDONG, 2002). Segundo Bressan et al. (2011), a importância dessas instituições é demonstrada na quantidade de cooperados que elas possuem atualmente e na movimentação financeira que acontece no segmento.

No início da década de 80 já existiam 430 cooperativas de crédito em pleno exercício no Brasil. Em um estudo disponibilizado pelo Bacen (2015), é exposto a representatividade, em termos de volume de crédito em operação, representado por $2,84 \%$, que as cooperativas movimentam no sistema financeiro nacional.

Em 2015, existiam, aproximadamente, 1.100 cooperativas de crédito em plena atuação no país que juntas somavam o montante de $\mathrm{R} \$ 180$ bilhões em ativos totais. Esse valor as colocava em sexta posição no quadro geral de instituições financeiras com mais operações financeiras no sistema nacional, abaixo apenas do Banco do Brasil, Itaú, Caixa Econômica Federal, Bradesco e Santander (BACEN, 2015).

Em termos percentuais de crescimento temporal das operações de crédito das cooperativas no país, tem-se números graduais e significativos. No ano de 1997, o total de operações de crédito realizadas por cooperativas somava $0,74 \%$, passando para $2,14 \%$ em 2005 (FERREIRA, GONÇALVES e BRAGA, 2007), e em 2015, segundo Bacen (2015), para 2,84\%, comprovando o crescimento e importância do segmento.

$\mathrm{O}$ estado de Minas Gerais se destaca quanto à participação das cooperativas de crédito. Há 792 cooperativas no estado, das quais 198 são de crédito. O ramo de cooperativismo de crédito é o que mais se destaca dentre todos que possuem um rápido crescimento de associados e empregados, tendo acrescido seu número em 4,3\% e 3,2\% no ano de 2014 e 2015, respectivamente. Considerando o PIB do estado, nota-se também uma representatividade do cooperativismo, que participa com $6,4 \%$ do PIB total. Dentre esse percentual tem-se como referência o cooperativismo agropecuário e de crédito, representando 40,93\% e 37,69\%, respectivamente (OCEMG, 2016).

Assim, Pinheiro (2008) coloca que é notório o crescimento e importância do setor de cooperativismo de crédito, porém ainda não se tem conhecimento suficiente para que se torne completamente eficiente. Segundo o autor citado, muito ainda se tem que aprender e aprimorar nas metodologias usadas na gestão de eficiência das cooperativas.

Dada a representatividade do crédito cooperativo no Brasil e no estado de Minas Gerais, torna-se relevante a análise da eficiência tida pelas cooperativas de crédito como forma de identificar as melhores práticas, tendo como base as mais eficientes, e melhorar a perspectiva de crescimento da modalidade. Assim, o objetivo geral deste trabalho foi analisar, conforme o porte, a eficiência alcançada pelas cooperativas de crédito de Minas Gerais no período de 2013 a 2015.

Foram ainda estabelecidos os seguintes objetivos específicos: (a) analisar a eficiência produtiva, eficiência técnica e a eficiência de escala; (b) analisar os escores de eficiência de escala e os escores encontrados através da fronteira normalizada; (c) analisar as cooperativas de crédito referenciais encontradas no modelo.

A necessidade de avaliação de eficiência das cooperativas está ligada ao fato de sua significância e seu papel na sociedade, enquanto descentralizadoras de renda, uma vez que são organizações sem fins lucrativos. Quanto maior for o conhecimento e a rapidez pela qual a dissemina, melhores serão os resultados advindos da cooperação. Assim, justifica-se o estudo destas sociedades e o aprimoramento em sua gestão (VILELA; NAGANO; MERLO, 2007).

Vale destacar ainda, conforme exposto por Borges (2015), que a busca por uma análise mais assertiva acerca da administração dessas instituições ainda é pouco explorada, sendo um caminho aberto a se percorrer. Concomitantemente, a metodologia utilizada para se inferir sobre a eficiência pode auxiliar em decisões mais acertadas em meio à subjetividade gerencial presente nesse tipo de organização.

\section{REFERENCIAL TEÓRICO}

Neste tópico do trabalho serão expostos alguns conceitos já apresentados sobre o tema em questão e que servirão de parâmetro para as futuras inferências.

A Resolução BACEN n ${ }^{\circ} 2.771$, de 30 de agosto de 2000 regulamenta em duas definições as cooperativas de crédito, sendo de crédito mútuo e de crédito rural. Os critérios para associação são: para cooperativas de crédito mútuo, as pessoas de determinadas classes de trabalhadores de diferentes ramos que se interessarem em associar; para as cooperativas de crédito rural, todas as pessoas que possuem alguma atividade voltada ao ambiente rural. As 
cooperativas de crédito de livre admissão, uma modalidade regulamentada em 2003, abrem espaço para qualquer pessoa, de qualquer ramo de atuação, se tornar associado e essas são regidas pela Resolução n 3.442, de 2007.

As cooperativas de crédito integram o Sistema Financeiro Nacional e ocupam a sexta posição no ranking das instituições com mais operações financeiras no sistema. Estão aptas a captar recursos junto ao seu público associado e, então, cria moeda escritural como um banco convencional, não podendo ser considerada um banco pelo caráter cooperativo e assim são denominadas como "cooperativas de crédito" (BACEN, 2002).

Segundo Bittencourt (2003), as cooperativas de crédito são associações de pessoas que fornecem os mesmos serviços prestados pelas instituições bancárias: financia a produção e os investimentos, cobre contas, talões de cheques e opções de investimento para os associados. Por outro lado, difere de um banco, pois os proprietários são os próprios clientes. Dessa forma, segundo Assaf Neto (2000), uma cooperativa de crédito consiste numa instituição financeira não bancária, entidade que viabiliza crédito aos seus associados.

Vilela, Nagano e Merlo (2007), classificaram as cooperativas de crédito de acordo com o modo que as mesmas estão ligadas aos seus associados e as ordenaram em graus. Como cooperativa de primeiro grau ou singulares, tem-se a proximidade direta com o associado. As denominadas de segundo grau, envolvem várias de primeiro grau e tem como objetivo dar força as primeiras. E por fim, as cooperativas de terceiro grau que englobam as de segundo grau e são responsáveis por tratar diretamente com os órgãos regulamentadores do segmento.

Várias são as definições e classificações destas organizações. Bialoskorski Neto (2007) coloca que elas buscam o beneficiamento dos associados mutuamente e que existem com basicamente duas funções: desempenharse bem em determinado período e distribuir os resultados/ sobras aos associados ao findar-se tal tempo; em outro aspecto, alcançar o desempenho de uma forma que os bons resultados possam ser imediatamente retornados aos associados na forma de melhores condições da prestação de serviços e melhores preços na venda de insumos e aquisição de produtos, diferentemente de organizações convencionais que focam primeiramente em atingir bons resultados e indiretamente retornar os lucros aos acionistas.

Nesse sentido, expondo as principais diferenças de organizações cooperativas e das organizações convencionais, Cuevas e Fischer (2006), dizem que uma das diferenças e vantagens claras tidas por cooperativas é a solução que acontece naturalmente da seleção adversa, uma vez que seus clientes são também seus donos e buscam o mútuo desenvolvimento. Em contrapartida, em instituições convencionais, esse aspecto é arduamente controlado através do racionamento creditício.

Como qualquer outra instituição, existem adversidades no cooperativismo, Branch, Baker e Chapter (2000) colocam algumas delas em pauta, como por exemplo, a diversidade da natureza dos associados, visto que alguns se associarão com o intuito de tomar empréstimos e outros em poupar. Assim, tem-se a necessidade de conciliação de interesse entre eles e uma maior efetividade no controle da gerência, visto que o objetivo central das cooperativas de crédito é promover o desenvolvimento, sem aferir lucro, dos agentes poupadores e tomadores de empréstimos.

Nesse sentido, Antonialli (2000) enfatiza a necessidade de um elevado grau de habilidade vindo da gerência, visto a dificuldade em harmonizar os interesses político, social e econômico dos cooperados, ligados ao desenvolvimento cooperado/cooperativa, assistência social a ser prestada e representatividade da cooperativa para com a sociedade, respectivamente. Dessa forma, a eficiência gerencial dessas organizações se torna uma variável complexa de ser estudada.

Alguns fatores podem ser considerados primordiais para análise de eficiência. Ferreira Gonçalves e Braga (2007), defendem que um desses fatores é a exclusividade nas concessões e captações dos recursos, visto que os contemplados com tais atividades são apenas os cooperados. Em maioria, eles estão concentrados na mesma região, assegurando também o papel socioeconômico da cooperativa, que estando presente em localidades não contempladas por instituições financeiras convencionais, ganham espaço para promover o desenvolvimento (CHAVES, 2006).

Outro fator preponderante resulta no fato de cooperativas não destinarem suas atividades à geração de lucro, mas sim ao custeio das atividades dos cooperados. Os excedentes de capital possuídos pelas cooperativas são denominados sobras, tais quais são repassados aos cooperados proporcionalmente às suas movimentações financeiras no período e podem interferir diretamente na diminuição ou aumento das taxas de concessão e aplicações dos recursos, respectivamente.

A eficiência, como colocado por Nakagawa (1987), está diretamente relacionada com o que se consome na produção e o produto final adquirido, colocando em pauta o processamento e a metodologia utilizada. Complementando, Bialoksorski Neto(2004) expõe que o conceito de eficiência econômica está ligado com o 
conhecimento do que foi investido, de forma que seja possível o máximo aproveitamento, calculado pelo que será alcançado. As cooperativas, após sua análise de objetivos, não diferem, pois, à luz da relação entrada/saída (input/output), é possível mensurar tal grau de eficiência.

Assim, um alto grau de eficiência é dado pela quantidade máxima de produção com um mínimo de recursos aplicados (DIAS, 2011). Concernente a isso, Apergis e Alevizopoulou (2011), explanam que eficiência pode ser medida com a alocação de certa quantidade de recursos e a resposta exata de produtos finais almejados.

A eficiência pode ser medida também com base em duas fronteiras, produção e custo. A fronteira de produção determina o quanto se pode produzir ao máximo para um determinado nível de insumos e a fronteira de custo determina o quanto se tem de custo ideal para cada nível de produção. Nesse sentido, têm-se como eficientes as organizações que se encaixarem devidamente nas fronteiras, atentando-se para a relação entrada/saída (JUNOY, 2000).

Ferreira Gonçalves e Braga (2007), analisaram o desempenho das Cooperativas de Economia e Crédito Mútuo de Minas Gerais, por meio da Análise Envoltória de Dados (DEA), a partir de indicadores contábeis e financeiros de 105 cooperativas de crédito no ano de 2003. Os resultados demonstraram que as cooperativas operavam naquele ano com grande ineficiência técnica, sendo mais eficientes em termos de escala.

Vilela, Nagano e Merlo (2007) aplicara o método de Análise Envoltória de Dados (DEA) para avaliar o desempenho das cooperativas de crédito rural do estado de São Paulo, nos anos de 2001 e 2002. Os resultados apontaram que cooperativas que possuíam maior volume de crédito concedido, dada a relação entre ativo total e despesas administrativas se apresentaram como as mais eficientes entre as cooperativas analisadas.

Borges (2015) analisou a eficiência das cooperativas de crédito de Minas Gerais nos anos de 2012 e 2013, com uso da metodologia DEA, a qual possibilitou a inferência em vários aspectos da eficiência gerencial. Foram encontradas as cooperativas totalmente eficientes que serviram como benchmarking para outras por grupo de indicadores, como solvência e liquidez e capital e risco.

Höher, De Souza e Fochezatto (2019), analisaram as cooperativas financeiras do Rio Grande do Sul, buscando responder se existe uma associação entre a eficiência das cooperativas de crédito com os sistemas que atuam (SICREDI, CRESOL, CREHNOR, UNICRED E SICOOB), por meio da metodologia DEA, no período de 2013 a 2016. Os resultados demonstraram um equilíbrio, quanto à eficiência, entre as cooperativas financeiras estabelecidas no Rio Grande do Sul, bem como a constatação de que a eficiência não está associada ao tamanho (Ativo total), nem a vinculação a determinado sistema.

\section{PROCEDIMENTOS METODOLÓGICOS}

Dentre as metodologias disponíveis utilizadas para cálculo de eficiência em cooperativas, optou-se em usar neste trabalho a Análise Envoltória de Dados (DEA), que mensura eficiência através da relação input/output e estabelece pontos de referência, sendo as cooperativas com grau máximo de eficiência, fornecendo uma fronteira que permite avaliar como eficiente ou ineficiente as unidades avaliadas, denominadas DMU's (Unidades Tomadoras de Decisão).

A eficiência fornecida por esta metodologia permite uma análise mais aprofundada de unidades que atuam no mesmo ramo e oferecem os mesmo produtos e serviços (DMU's), sendo uma análise a frente de metodologias como a avaliação dos indicadores financeiros que de certo modo isola certas informações ao se analisar separadamente, além de prover análises unificadas e seguras como parâmetro para o segmento cooperativo.

\subsection{Análise Envoltória de Dados}

Os cálculos de eficiência utilizando a metodologia DEA foram iniciados por Farrel (1957), que estipulou uma entrada e uma saída como variáveis para a investigação. Com o resultado, era obtido um modelo referencial de organização eficiente e então se classificariam as outras organizações como eficientes se iguais a referência ou ineficientes se diferentes. Este estudo abriu espaço para que novas formas aprimoradas de se calcular fossem exploradas. Dando continuidade à linha, Farrel, Charnes, Cooper e Rhodes (1978) exploraram o mesmo método de cálculo, porém inserindo vários inputs e vários outputs com um modelo não paramétrico, o que será usado no caso deste estudo (VILELA; NAGANO; MERLO, 2007).

Teve-se a opção de dois modelos para o cálculo da eficiência, com denominações de orientado a output e orientado a input. Neste trabalho, foi escolhido o modelo orientado a output, ou seja, buscará por níveis ótimos de produtos, considerando níveis de inputs fixados. É um modelo de programação linear e pode ser descrito pela Equação 1:
$\operatorname{Max} \_(\varphi, \lambda) \varphi$
s.a $\varphi$ yi $-\mathrm{Y} \lambda \leq 0$
$-\mathrm{xi}+\mathrm{X} \lambda \leq 0$
$-\lambda \leq 0$ 
em que yi é um vetor ( $\mathrm{m} \times 1)$ de quantidades de produto da i-ésima DMU; xi, um vetor ( $\mathrm{k}$ x 1) de quantidades de insumo da i-ésima DMU; Y, uma matriz ( $\mathrm{n}$ x m) de produtos das n DMUs; $\mathrm{X}$, uma matriz ( $\mathrm{n} \mathrm{x}$ ) de insumos das $n$ DMUs; $\lambda$, um vetor ( $\mathrm{n} \times 1$ ) de pesos; e $\varphi$, uma escalar que tem valores iguais ou maiores do que $1 \mathrm{e}$ indica $o$ escore de eficiência das DMUs, em que um valor igual a 1 indica eficiência técnica relativa da i-ésima DMU, em relação às demais, e um valor maior do que 1 evidencia a presença de ineficiência técnica relativa. Nesse ponto, é oportuno destacar que, de modo geral, utiliza-se como escore de eficiência a razão $1 / \varphi$ (inverso do índice $\varphi$ ), o que condiciona valores variando entre 0 e 1 , sendo " 1 " determinado por $\varphi=1$, o que deve ser interpretado como máxima eficiência relativa. $\mathrm{O}(\varphi-1)$ indica o aumento proporcional nos produtos que a i-ésima DMU pode alcançar, mantendo constante a quantidade de insumo, e determinará, na presença de ineficiência, escores menores que 1 (FERREIRA; GONÇALVES; BRAGA, 2007, p. 428).

As medidas de eficiência podem se decompor em três: eficiência produtiva, eficiência técnica e eficiência de escala. Das três, as duas primeiras são calculadas isoladamente através de dois modelos diferentes, CCR (Charnes, Cooper \& Rhodes, 1978) e BCC (Banker, Charnes \& Cooper, 1984). O CCR mede a eficiência considerando aumentos constantes nos produtos e insumos, representados por uma reta no plano, à medida que os níveis de insumos são aumentados, aumenta-se proporcionalmente os níveis de produtos. Este modelo foi descrito na expressão 1 (ANGULO MEZA et al, 2005).

Já o modelo BCC insere uma restrição de convexidade no modelo padrão CCR, permitindo que os retornos não necessariamente tenham que ser constantes e torna $\mathrm{o}$ modelo mais flexível à medida em que possibilita retornos variáveis a escala, formando uma fronteira curva de eficiência. A Equação 2 ilustra o modelo CCR adaptado ao BCC:

$\operatorname{Max}(\varphi, \lambda) \varphi$

s.a $\varphi y i-\mathrm{Y} \lambda \leq 0$

$-\mathrm{xi}+\mathrm{X} \lambda \leq 0$

$\mathrm{N} 1^{\wedge} \wedge \lambda=1$

$-\lambda \leq 0$

em que N1 é um vetor ( $\mathrm{n} \times 1$ ) de números uns (FERREIRA; GONÇALVES; BRAGA, 2007)

As unidades classificadas como eficientes são aquelas que estão sobre as fronteiras, tanto no modelo CCR quanto no BCC, como mostra a Figura 1.

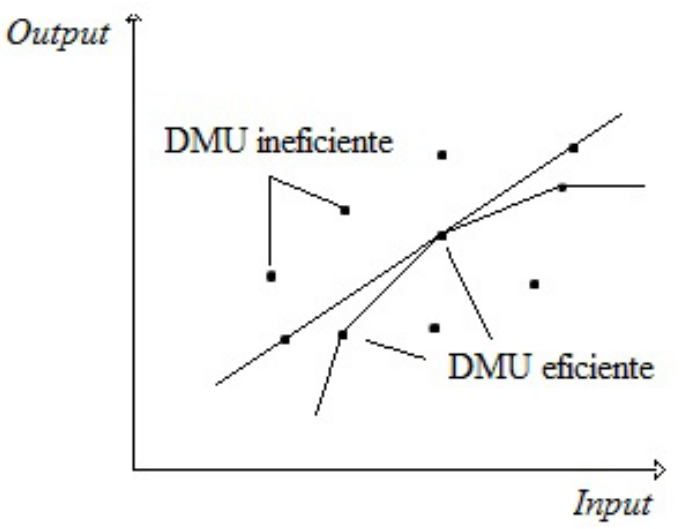

FIGURA 1 - Fronteira de eficiência considerando retornos variáveis e constantes a escala.

Fonte: Adaptado de Ângulo Meza et al, 2015.

Já a eficiência de escala é medida a partir dos cálculos das outras duas e obtida pela razão das mesmas. Esta mede se de fato as unidades são eficientes ou ineficientes, caracterizando eficiência se o valor da razão for igual a 1 ou ineficiência se o valor da razão for diferente de 1. Este escore pode ser calculado pela Equação 3:

$E S=\frac{E T_{C C R}\left(X_{k}, Y_{k}\right)}{E T_{B C C}\left(X_{k}, Y_{k}\right)}$

em que $E T_{C C R}\left(X_{k} Y_{k}\right)$ é a eficiência produtiva adquirida do modelo de retornos constantes a escala e $E T_{B C C}\left(X_{k}, Y_{k}\right)$ é a eficiência técnica encontrada no modelo com retornos variáveis a escala.

A fim de dar mais consistência a análise da eficiência de DMU's, novas formas de se calcular este escore foram sendo adaptadas aos modelos existentes. O software utilizado para os cálculos deste trabalho foi o SIAD (Sistema Integrado de Apoio a Decisão), que segundo Meza (2003, p. 6), "[...] permite trabalhar com até 100 DMUs e 20 variáveis, entre inputs e outputs" o que, a partir do momento da divisão dos portes das cooperativas, atendeu aos requisitos deste trabalho.

Este software proporciona resultados de quatro índices diferentes e possibilita a análise detalhada dos dados, além de estabelecer as condições de melhoria para as DMU's. O primeiro índice é a fronteira padrão, obtida pela aplicação dos modelos citados na forma padrão. $\mathrm{O}$ segundo fornece a fronteira invertida, que inverte os valores de input e output permitindo a comparação dos escores de forma contrária. 
A fronteira invertida então, classifica as DMU's como as que possuem as piores práticas do ponto de vista padrão, ou seja, escores altos na fronteira invertida denota que elas possuem um desempenho ruim, considerando os eixos do gráfico padronizados, mas quando invertidos, output passa a ser considerado input e input passa a ser considerado output, tem-se que altos escores denotam eficiência. Esta prática permite avaliar dois pontos de vistas de cada DMU. Também permite eliminar DMU's que são falsos eficientes (MEZA et al., 2005). A Figura 2 ilustra essa situação:

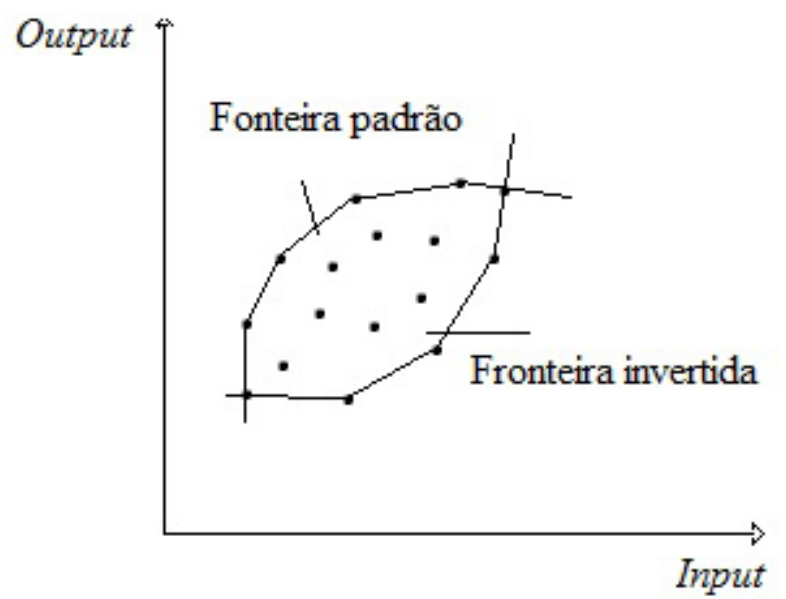

FIGURA 2 - Fronteira padrão e Fronteira invertida Fonte: Adaptado de Ângulo Meza et al, 2015

O terceiro e quarto índice fornecem a fronteira composta e fronteira normalizada de eficiência, que podem ser calculadas da seguinte maneira, respectivamente (MEZA et al, 2005):

Eficiência Composta $=\frac{\text { Eficiência Padrão }+(1-\text { Eficiência Invertida })}{2}$
Eficiência Composta Normalizada $=\frac{\text { Eficiência Composta }}{\text { Máxima Eficiência composta }}$

Os cálculos destas duas eficiências podem fornecer a informação da DMU mais eficiente de toda amostra, permitindo a análise aprofundada de suas práticas. A análise de eficiência composta e normalizada auxilia a análise ao considerar a DMU mais eficiente de toda a amostra, diferentemente dos modelos de escala, padrão e invertida. Por fim, com esta prática se completa a análise. Estas informações foram readaptadas para este trabalho através da pesquisa realizada por Neves Junior et al. (2012).

\subsection{Característica da Amostra}

A coleta de dados foi realizada diretamente do site do Banco Central do Brasil, que disponibiliza grande parte das contas de resultado e patrimoniais das cooperativas. A partir disso, foram escolhidas as variáveis que seriam classificadas como entrada/inputs e as variáveis de saída/ outputs necessários na metodologia.

De todas as 198 cooperativas (DMU's) em atividade no estado de Minas Gerais, foram selecionadas 161para compor a amostra, uma vez que as demais não possuíam as informações nos anos de 2013 a 2015 e, então, foram excluídas. A maioria das cooperativas extraídas para a amostra disponibilizam suas contas semestralmente. Para melhor avaliação, as contas de cada semestre foram somadas e obtidos valores anuais.

Buscando uma melhor avaliação de eficiência das cooperativas, utilizou-se a técnica estatística de divisão de quartis para a separação por porte, ou seja, foram analisadas as cooperativas de pequeno, médio e grande porte, baseado em seu ativo total acumulado. As $25 \%$ (40) primeiras cooperativas, das 161 , foram classificadas como pequenas, as $50 \%$ (81) que se encontravam na mediana dos dados foram consideradas médias e as $25 \%$ (40) últimas foram consideradas grandes. Essa divisão faz com que os cálculos dos escores não sejam enviesados, uma vez que o ativo total é uma variável de saída do modelo.

A separação foi feita considerando 3 portes, sendo pequena as que possuíam valores na faixa do $1^{\circ}$ quartil, média com valores na faixa do $2^{\circ}$ quartil e as grandes com valores no intervalo do $3^{\circ}$ quartil, como mostra a Tabela 1.

O propósito exploratório do trabalho ajudou na aplicabilidade e medição dos resultados encontrados pela metodologia DEA, justificado pela necessidade de avaliação e desempenho das unidades cooperativas de crédito do estado, em busca de boas práticas de gestão.

Os dados estatísticos foram calculados para ser possível observar a média dos escores de eficiência e sua variação, levando em consideração o tempo e o porte das cooperativas analisadas.

Foram selecionadas as variáveis denominadas inputs/insumos, sendo Despesas Administrativas e Despesas de Captação e outputs/produtos Operações de crédito, Sobras ou Perdas e Ativo Total. A escolha das variáveis de entrada e saída se baseou no fato de serem as principais contas que possam melhor representar os resultados destas sociedades, dado que são comuns a todas as cooperativas. 
TABELA 1 - Divisão dos quartis por porte e ano

\begin{tabular}{cccc}
\hline & $1^{\circ}$ Quartil & $2^{\circ}$ Quartil & $3^{\circ}$ Quartil \\
\hline \multirow{2}{*}{2013} & \multirow{2}{*}{ Até $\mathrm{R} \$ 133,568,301.05$} & $\mathrm{R} \$ 133,568,301.05 \mathrm{a}$ & $\mathrm{R} \$ 684,569,880.8 \mathrm{a}$ \\
& $\mathrm{R} \$ 684,569,880.8$ & $\mathrm{R} \$ 4,538,378,617$ \\
\hline \multirow{2}{*}{2014} & \multirow{2}{*}{ Até $\mathrm{R} \$ 159,566,152.6$} & $\mathrm{R} \$ 159,566,152.6 \mathrm{a}$ & $\mathrm{R} \$ 851,524,818.9 \mathrm{a}$ \\
& \multirow{2}{*}{2015} & $\mathrm{R} \$ 851,524,818.9$ & $\mathrm{R} \$ 5,729,147,171$ \\
& \multirow{2}{*}{ Até $\mathrm{R} \$ 185,433,763$} & $\mathrm{R} \$ 185,433,763.1 \mathrm{a}$ & $\mathrm{R} \$ 1,046,075,997 \mathrm{a}$ \\
& & $\mathrm{R} \$ 1,046,075,997$ & $\mathrm{R} \$ 7,280,103,536$ \\
\hline
\end{tabular}

Fonte: Elaborado pelos autores

Para determinar os escores de eficiência foi utilizado o software SIAD (Sistema Integrado de Apoio a Decisão), dando foco ao modelo com retornos variáveis a escala e em todos os cálculos considerando orientação produto do modelo, em que se procura níveis otimizados de produtos, dado determinados níveis de insumos.

De acordo com Charnes et al. (1994), a metodologia DEA otimiza cada observação individual com o objetivo de calcular uma fronteira discreta por partes, determinada pelo conjunto de DMUs eficientes em Pareto, em contraste com as abordagens paramétricas cujo objetivo é otimizar um único plano de regressão por meio dos dados. Além disso, a abordagem paramétrica requer a imposição de uma forma funcional, a qual requer suposições específicas sobre a distribuição dos termos de erro. A DEA não requer nenhuma suposição sobre a forma funcional e calcula uma medida de desempenho máximo para cada DMU em relação a todas as outras DMUs na população observada, com o único requisito de que cada DMU esteja na fronteira ou abaixo dela.

\section{RESULTADOS E DISCUSSÃO}

\subsection{Eficiência Técnica e de Escala}

Foram consideradas unidades eficientes as que atingiram um escore maior ou igual a $90 \%(\mathrm{E}>90 \%)$ nos modelos CCR e BCC e também nos escores de escala. As unidades ineficientes obtiveram escores abaixo de $90 \%$ $(\mathrm{I}<90 \%)$.

Pode-se analisar a partir da Tabela 2 que as quantidades de cooperativas eficientes encontradas pelo modelo que considera retornos constantes a escala (CCR) se mantiveram em níveis aproximados no $1^{\circ}$ quartil de 2013, 2014 e 2015. No modelo que considera retornos variáveis a escala (BCC) houve uma tendência parecida, com a quantidade variando de $57,5 \%$ a $67,5 \%$ do total de cooperativas ao longo do tempo. Leva-se em conta que a eficiência encontrada nos escores do CCR, representam a performance produtiva, obtida com base no quociente do foi produzido e o que se gastou para produzir. Já os escores do BCC indicam a eficiência técnica, baseada na utilização dos insumos considerados e sua capacidade de gerar mais produtos para aquele mesmo nível de insumos.

Considerando o modelo CCR, o número de cooperativas eficientes foi significativamente menor quando comparados ao modelo BCC, fator esse que se deve a rigidez quando se trata de retornos constantes a escala, quando a área de solução viável é menor, sendo adequado seus resultados somente se as cooperativas operassem em escala ótima. Assim, somente $17,5 \%, 22,5 \%$ e $12,5 \%$ das pequenas cooperativas de crédito analisadas nos três anos possuíam eficiência produtiva, o que representa que a maior parcela das pequenas cooperativas em análise pode aumentar os serviços prestados como os empréstimos, gerar melhores resultados, com consequente crescimento, traduzido no ativo total, sem ampliar gastos.

O modelo mais flexível (BCC), chamada pura eficiência técnica por ser apurado sem captar os efeitos da eficiência de escala, encontrou um número maior de cooperativas eficientes em todos os anos, visto que permite a variação dos níveis de insumo para níveis fixados de produtos e vice-versa, sendo o percentual de pequenas cooperativas eficientes correspondentes a $57,5 \%, 60 \%$ e $67,5 \%$ em 2013, 2014 e 2015, respectivamente.

Segundo Belloni (2000), a eficiência técnica denota a habilidade da gerência em otimizar e direcionar os recursos da melhor forma. Nas cooperativas pequenas, esse fato pode estar aliado à sua proximidade com seus associados e ao fato de possuírem uma relação estreita com os mesmos, possibilitando o melhor desenvolvimento mútuo. Percebe-se uma tendência crescente no número de cooperativas eficientes neste modelo, ou seja, as pequenas cooperativas buscaram aprimorar suas técnicas administrativas. 
TABELA 2 - Eficiência dos modelos CCR, BCC e eficiência de escala no $1^{\circ}$ quartil dos anos 2013, 2014 e 2015

\begin{tabular}{ccccccc}
\hline & \multicolumn{2}{c}{ CCR } & \multicolumn{2}{c}{ BCC } & \multicolumn{2}{c}{ Escala } \\
\hline $1^{\circ}$ Quartil 2013 & $\mathrm{n}$ & $\%$ & $\mathrm{n}$ & $\%$ & $\mathrm{n}$ & $\%$ \\
\hline Unidades eficientes & 7 & $17.5 \%$ & 23 & $57.5 \%$ & 11 & $27.5 \%$ \\
Unidades Ineficientes & 33 & $82.5 \%$ & 17 & $42.5 \%$ & 29 & $72.5 \%$ \\
Total & 40 & $100.0 \%$ & 40 & $100 \%$ & 40 & $100.0 \%$ \\
\hline $1^{\circ}$ Quartil 2014 & & & & & & \\
\hline Unidades eficientes & 9 & $22.5 \%$ & 26 & $65.0 \%$ & 11 & $27.5 \%$ \\
Unidades Ineficientes & 31 & $77.5 \%$ & 14 & $35.0 \%$ & 29 & $72.5 \%$ \\
Total & 40 & $100.0 \%$ & 40 & $100.0 \%$ & 40 & $100.0 \%$ \\
\hline $1^{\circ}$ Quartil 2015 & & & & & & \\
\hline Unidades eficientes & 5 & $12.5 \%$ & 27 & $67.5 \%$ & 8 & $20.0 \%$ \\
Unidades Ineficientes & 35 & $87.5 \%$ & 13 & $32.5 \%$ & 32 & $80.0 \%$ \\
Total & 40 & $100.0 \%$ & 40 & $100.0 \%$ & 40 & $100.0 \%$ \\
\hline
\end{tabular}

Fonte: Resultados da pesquisa

Com relação a eficiência de escala que mede a eficiência baseado nos índices CCR e BCC, tem-se que as pequenas cooperativas analisadas em todos os anos apresentaram, em sua maioria, ineficiência, visto que em $2013,72,5 \%$ das cooperativas eram consideradas ineficientes e em $2015,80 \%$ foram ineficientes.

É relevante destacar que a eficiência de escala mede o quanto pode afetar na escala de processamento das cooperativas as mudanças feitas na forma de se disponibilizar crédito aos seus associados, ter capacidade de aferir sobras e acumular ativos sem gastos desnecessários. Assim, estes fatos podem retornar índices altos ou baixos de eficiência nesta medida.

Em síntese, as cooperativas de pequeno porte possuem desempenho médio quando se trata de suas decisões gerenciais, observado no escores no modelo BCC. Quando analisada sua eficiência de escala, nota-se que há muito o que se melhorar em sua capacidade operacional, uma vez que esta medida de eficiência considera o quanto estão sendo otimizados os espaços das plantas produtivas, ou seja, capacidade operacional, da cooperativa. Neste caso, então, as pequenas cooperativas necessitam realizar a reorganização de seus arranjos, buscando eliminar a sua capacidade ociosa.

Na Tabela 3, observando os escores adquiridos das cooperativas de médio porte, nota-se a mesma tendência encontrada no primeiro. $\mathrm{O}$ modelo $\mathrm{CCR}$, mais rígido, com altos níveis de ineficiência e o modelo $\mathrm{BCC}$ com uma flexibilidade maior, deixando a fronteira de eficiência mais abrangente, porém em proporção menor que o $1^{\circ}$ quartil.
No modelo CCR, as cooperativas ineficientes se demonstraram crescentes ao longo do tempo, representando $71,6 \%, 76,5 \%$ e $84 \%$ das cooperativas analisadas em 2013, 2014 e 2015, respectivamente. Estes índices permitem dizer que as cooperativas de porte médio podem melhorar em média $77,4 \%$ os seus níveis de produtos, mantendo fixo os seus níveis de insumos (SOUZA; BRAGA; FERREIRA, 2011).

No modelo BCC, os índices de eficiência se mantiveram quase constantes, com um pequeno aumento de aproximadamente 11 pontos percentuais das cooperativas ineficientes do ano de 2013 para 2015. Em geral, pode-se dizer também que boa parte das cooperativas de médio porte sofrem com a má alocação e distribuição dos recursos, devido às ineficientes tomadas de decisão gerenciais.

No que diz respeito à eficiência de escala deste quartil, que analisa as cooperativas consideradas de porte médio, quando comparada ao primeiro quartil, tem-se quantidades maiores de unidades eficientes, que utilizam com maior aproveitamento sua capacidade operacional e promove a não subutilização de capacidade de atender a demanda de seus cooperados por seus serviços. Assim, nota-se também que, neste ponto, as cooperativas de médio porte, em sua maioria, necessitam menos que as de pequeno porte de reorganizar os seus planos de produção, fato concernente aos resultados encontrados por Souza, Braga e Ferreira (2011), que relatam resultado semelhante quanto a eficiência das cooperativas de pequeno porte. 
TABELA 3 - Eficiência dos modelos CCR, BCC e eficiência de escala no $2^{\circ}$ quartil dos anos 2013, 2014 e 2015

\begin{tabular}{ccccccc}
\hline & \multicolumn{2}{c}{$\mathrm{CCR}$} & \multicolumn{2}{c}{ BCC } & \multicolumn{2}{c}{ Escala } \\
\hline $20132^{\circ}$ Quartil & $\mathrm{n}$ & $\%$ & $\mathrm{n}$ & $\%$ & $\mathrm{n}$ & $\%$ \\
\hline Unidades eficientes & 23 & $28.4 \%$ & 38 & $46.9 \%$ & 55 & $67.9 \%$ \\
Unidades Ineficientes & 58 & $71.6 \%$ & 43 & $53.1 \%$ & 26 & $32.1 \%$ \\
Total & 81 & $100.0 \%$ & 81 & $100.0 \%$ & 81 & $100 \%$ \\
\hline $20142^{\circ}$ Quartil & & & & & & \\
\hline Unidades eficientes & 19 & $23.5 \%$ & 27 & $33.3 \%$ & 55 & $67.9 \%$ \\
Unidades Ineficientes & 62 & $76.5 \%$ & 54 & $66.7 \%$ & 26 & $32.1 \%$ \\
Total & 81 & $100.0 \%$ & 81 & $100.0 \%$ & 81 & $100.0 \%$ \\
\hline $20152^{\circ}$ Quartil & & & & & & \\
\hline Unidades eficientes & 13 & $16.0 \%$ & 29 & $35.8 \%$ & 35 & $43.2 \%$ \\
Unidades Ineficientes & 68 & $84.0 \%$ & 52 & $64.2 \%$ & 46 & $56.8 \%$ \\
Total & 81 & $100.0 \%$ & 81 & $100.0 \%$ & 81 & $100.0 \%$ \\
\hline
\end{tabular}

Fonte: Resultados da pesquisa

Vale ressaltar que, mesmo estando mais eficiente em relação as cooperativas pequenas, nota-se uma queda significativa no número de cooperativas eficientes na medida de escala em 2015, fato que pode ser justificado pelo crítico cenário econômico brasileiro do ano de 2014 até o ano de 2015. Este fato faz com que seja necessária uma reavaliação e adaptação quanto à sua escala de atividade com sua capacidade realmente instalada.

O $3^{\circ}$ quartil contempla as 40 cooperativas com maiores ativos da amostra, sendo consideradas de grande porte. Percebe-se, através da Tabela 4, em todos os anos que essas cooperativas possuem um grau de sensibilidade menor em seus índices, ao passo que não se obteve modificações expressivas nas quantidades eficientes e ineficientes encontradas.

A eficiência técnica obtida pelas cooperativas grandes, se mostram maiores do que as adquiridas pelas médias, com $40 \%, 50 \%$ e $42,5 \%$ de cooperativas eficientes nos três anos de análise respectivamente e pode ser atribuída à uma capacidade na busca por mão de obra qualificada ou até mesmo qualificar os seus gestores em função de aumentar os seus produtos, uma vez que possuem mais visibilidade e recursos (SOUZA; BRAGA; FERREIRA, 2011). Assim como as médias e pequenas, as cooperativas eficientes do modelo CCR, por serem poucas demonstram que é possível aumentar significativamente seus níveis de produtos, crédito, sobras, ativo total, dado os seus insumos, ou seja, as despesas gastas.
Era esperado que sua eficiência de escala se mantivesse quase inalterada ao longo do tempo, uma vez que por serem de grande porte, estas cooperativas, de maneira geral, já possuem um arranjo físico operando em um nível fixo, sem causar efeitos bruscos nos índices de eficiência às mudanças que ocorrem em seu arranjo. No entanto, os resultados demonstraram que a situação atual operacional destas cooperativas não se encontra em bom patamar de eficiência, sendo que em todos os modelos e anos a quantidade de cooperativas eficientes não passa de $50 \%$ do total do quartil.

\subsection{Dados Estatísticos}

Quando considerado o modelo com retornos constantes a escala, ou seja, o aumento dos insumos gera proporcionalmente o aumento dos produtos, temse que os três portes de cooperativas responderam de maneira semelhante a esta fronteira, apenas com leve alta das médias das cooperativas, como pode se observar na Tabela 5.

Quanto ao modelo que permite retornos variáveis à escala (BCC), tem-se médias maiores nos três anos, dado que permite variações à escala, ou seja, diferentes cooperativas combinam de maneira diferente seus insumos, alcançando maior produtividade. No caso desse estudo, os insumos são representados pelos gastos operacionais para o funcionamento da cooperativa, de forma que essa combinação gere bom desempenho, atingindo a fronteira de eficiência. 
TABELA 4 - Eficiência dos modelos CCR, BCC e eficiência de escala no $3^{\circ}$ quartil dos anos 2013, 2014 e 2015

\begin{tabular}{ccccccc}
\hline & CCR & \multicolumn{3}{c}{ BCC } & \multicolumn{3}{c}{ Escala } \\
\hline 2013 3 Quartil & $\mathrm{n}$ & $\%$ & $\mathrm{n}$ & $\%$ & $\mathrm{n}$ & $\%$ \\
\hline Unidades eficientes & 7 & $17.5 \%$ & 16 & $40.0 \%$ & 10 & $25.0 \%$ \\
Unidades Ineficientes & 33 & $82.5 \%$ & 24 & $60.0 \%$ & 30 & $75.0 \%$ \\
Total & 40 & $100 \%$ & 40 & $100 \%$ & 40 & $100 \%$ \\
\hline 2014 3 Quartil & & & & & & \\
\hline Unidades eficientes & 10 & $25.0 \%$ & 20 & $50.0 \%$ & 12 & $30.0 \%$ \\
Unidades Ineficientes & 30 & $75.0 \%$ & 20 & $50.0 \%$ & 28 & $70.0 \%$ \\
Total & 40 & $100.0 \%$ & 40 & $100.0 \%$ & 40 & $100.0 \%$ \\
\hline 2015 3 Quartil & & & & & & \\
\hline Unidades eficientes & 9 & $22.5 \%$ & 17 & $42.5 \%$ & 10 & $25.0 \%$ \\
Unidades Ineficientes & 31 & $77.5 \%$ & 23 & $57.5 \%$ & 30 & $75.0 \%$ \\
Total & 40 & $100.0 \%$ & 40 & $100.0 \%$ & 40 & $100.0 \%$ \\
\hline
\end{tabular}

Fonte: Resultados da pesquisa

TABELA 5 - Resultados estatísticos dos escores encontrados no estudo

\begin{tabular}{|c|c|c|c|c|c|c|c|c|c|}
\hline & \multicolumn{3}{|c|}{ CCR } & \multicolumn{3}{|c|}{$\mathrm{BCC}$} & \multicolumn{3}{|c|}{ Escala } \\
\hline & Média & Mínimo & Desvio & Média & Mínimo & Desvio & Média & Mínimo & Desvio \\
\hline \multicolumn{10}{|l|}{$1^{\circ}$ Quartil } \\
\hline 2013 & 51 & 21 & 19.9 & 82 & 39 & 19.2 & 73 & 25 & 21 \\
\hline 2014 & 57 & 21 & 24.3 & 88 & 39 & 13.5 & 64 & 21 & 23.6 \\
\hline 2015 & 53 & 17 & 21.6 & 89 & 32 & 13.4 & 60 & 23 & 21.9 \\
\hline Média Geral & 53.7 & 19.7 & 21.9 & 86.3 & 36.7 & 15.4 & 65.7 & 23 & 22.3 \\
\hline \multicolumn{10}{|l|}{$2^{\circ}$ Quartil } \\
\hline 2013 & 73 & 31 & 18.1 & 82 & 37 & 16.4 & 89 & 45 & 11.7 \\
\hline 2014 & 67 & 27 & 19.2 & 74 & 34 & 20.1 & 91 & 51 & 10.5 \\
\hline 2015 & 61 & 28 & 18.6 & 75 & 38 & 19.2 & 82 & 28 & 15.2 \\
\hline Média Geral & 67 & 28.7 & 18.7 & 77 & 36.3 & 18.6 & 87.3 & 41.3 & 12.5 \\
\hline \multicolumn{10}{|l|}{$3^{\circ}$ Quartil } \\
\hline 2013 & 60 & 21 & 21.0 & 79 & 41 & 17.5 & 64 & 32 & 14.7 \\
\hline 2014 & 65 & 27 & 21.1 & 85 & 47 & 14.7 & 75 & 27 & 17.0 \\
\hline 2015 & 61 & 28 & 19.4 & 79 & 41 & 17.1 & 76 & 40 & 14.8 \\
\hline Média Geral & 62 & 25.3 & 20.5 & 81 & 43 & 16.4 & 71.7 & 33 & 15.5 \\
\hline
\end{tabular}

Fonte: Resultados da pesquisa 
Nas cooperativas de grande porte, obteve-se uma tendência estável e para as de pequeno porte crescente, considerando os três anos analisados. As cooperativas médias se mantiveram em níveis de eficiência, em média, mais elevados que as demais, utilizando suas contas operacionais de maneira mais adequada na geração de ativos, sobras e operações de crédito e sem desperdícios.

Os escores de escala analisam as cooperativas do ponto de vista de suas operações, ou seja, o quanto o aumento das operações realizadas pela cooperativa de crédito, implicam em maior produtividade, que está relacionada à capacidade dos gastos operacionais gerarem maior receita. Tem-se que os escores estão acima de $65 \%$ e as cooperativas de médio porte apresentam melhor desempenho. De maneira geral, pode-se dizer que os maiores escores de eficiência de escala estão presentes nas cooperativas de médio porte, tendo em vista, também, que seu desvio padrão é menor.

É válido dizer que se pode ter efeitos crescentes e decrescentes de escala, o que dá vantagens as cooperativas de médio porte, uma vez que as mesmas podem estar trabalhando com uso máximo de sua capacidade, número de funcionários, estrutura de maneira geral, de forma que sejam mais eficientes. As cooperativas pequenas podem, muitas vezes, terem muitos gastos e uma estrutura grande para o número de associados que atendem, possuindo um patamar mínimo de recursos já destinados a cobrirem estes gastos, o que acaba gerando resultados aquém do esperado. Já as grandes cooperativas, podem estar na linha decrescente de retornos, em que todos os gastos atuais para se manter já não geram mais resultados significativos.

Complementando a análise feita pelas médias dos escores de eficiência, foram calculados os desvios médios de eficiência de cada quartil do modelo, evidenciado na Tabela 5. Analisando estes, pôde-se identificar que, no geral, o modelo CCR, que mede a eficiência produtiva das cooperativas, teve resultados mais afastados da média e as cooperativas de médio porte foram as que menos variaram em torno desta média. Já no modelo em que a eficiência técnica é calculada, BCC, tem-se menos variação em torno da média, fato que se deu pela maior flexibilidade do modelo ao se medir a eficiência, tendo maior diversidade das cooperativas compondo a média das eficientes.

Quanto à eficiência de escala, obteve-se os maiores índices de desvio padrão para cooperativas de pequeno e grande porte e menor desvio para as cooperativas de médio porte. Isso pode ter se dado pelo fato de que a eficiência de escala considera juntamente os escores de eficiência produtiva e técnica, ou seja, algumas cooperativas não foram eficientes no quesito produtividade, mas as decisões técnicas tomadas supriram um pouco desta lacuna e vice-versa. No geral, este fato contribuiu para que os escores estivessem mais aproximados das médias.

\subsection{Eficiência Normalizada}

Em busca de melhor esmiuçar os dados e entender o bom funcionamento das cooperativas eficientes, calculou-se a fronteira invertida que forneceu informações precisas quanto às cooperativas referências, ou seja, as mais eficientes de toda amostra. A partir desta fronteira, foi possível ainda calcular a eficiência composta e a fronteira normalizada. Esta última, sendo a mais precisa por fornecer apenas uma como totalmente eficiente, será usada para estabelecer um ranking total por quartis, ou seja, identificar uma única cooperativa como a mais eficiente entre todas do quartil.

Estes cálculos evidenciaram o que já estava previsto, observando a Figura 2: as cooperativas que obtiveram bons escores de eficiência na fronteira padrão e baixo nível de eficiência na fronteira invertida, foram as mais bem colocadas na fronteira normalizada, uma vez que a fronteira invertida calcula a eficiência de modo contrário, considerando os inputs como outputs e os output como inputs. Assim, obteve-se os valores expressos na Tabela 6 :

TABELA 6 - Média simples dos escores de eficiência normalizada de cada quartil

\begin{tabular}{ccccc}
\hline & Ano & Média & Mínimo & Desvio \\
\hline 1 Quartil & 2013 & 58 & 23 & 18.5 \\
1 Quartil & 2014 & 60 & 22 & 14.3 \\
1 Quartil & 2015 & 62 & 18 & 14.9 \\
Média total & & & & $\mathbf{1 5 . 9}$ \\
2 Quartil & 2013 & 64 & 22 & 15.1 \\
2 Quartil & 2014 & 57 & 20 & 15.0 \\
2 Quartil & 2015 & 59 & 23 & 16.6 \\
Média total & & & & $\mathbf{1 5 . 6}$ \\
3 Quartil & 2013 & 64 & 22 & 15.0 \\
3 Quartil & 2014 & 66 & 32 & 10.2 \\
3 Quartil & 2015 & 59 & 27 & 13.3 \\
\hline Média total & & & & 12.8 \\
\hline
\end{tabular}

Fonte: Resultados da pesquisa 
De acordo com as médias, pode-se dizer que, ao longo do tempo, as cooperativas de grande porte buscaram se aprimorar em relação à eficiência, porém em níveis que podem não ter gerado resultado efetivo, uma vez que os escores de eficiência aumentaram em pequena escala. Esse fato se confirma ao analisar o intervalo dos escores de ineficiência que era no ano de 2013 de $22 \%$ a $100 \%$ e que chegou a ser de $32 \%$ a $100 \%$ em 2014. Assim, no geral, $10 \%$ das cooperativas desse quartil deixaram de ser ineficientes no passar de um período para outro.

Com a análise do desvio padrão dos escores de eficiência normalizada de cada porte das cooperativas expostos na Tabela 6 , notou-se menos variação nos escores das cooperativas de grande porte, ou seja, em cada ano de análise houve menos variabilidade nos índices de eficiência totais destas cooperativas em relação à média. Esse resultado pode ser decorrente do fato de as mesmas possuírem estruturas operacionais fixas e capacidade para captação de recursos mais rapidamente, de modo que, a curto prazo suprem suas ineficiências, não permitindo modificações bruscas em seus índices de eficiência. Nas cooperativas de pequeno e médio porte, as variações em torno das médias dos escores calculados foram praticamente as mesmas, fato evidenciado pelo desvio padrão em nível muito aproximado.

Comprovando a maior eficiência através da fronteira invertida e normalizada, observa-se na Tabela 7 os valores das cooperativas tidas como as mais eficientes em cada período e porte.

TABELA 7 - Dados da eficiência normalizada

\begin{tabular}{cccc}
\hline 2013 & BCC & Invertida & Normalizada \\
\hline 1 Quartil & $100 \%$ & $14 \%$ & $100 \%$ \\
2 Quartil & $100 \%$ & $32 \%$ & $100 \%$ \\
3 Quartil & $100 \%$ & $58 \%$ & $100 \%$ \\
2014 & & & \\
1 Quartil & $100 \%$ & $15 \%$ & $100 \%$ \\
2 Quartil & $100 \%$ & $30 \%$ & $100 \%$ \\
3 Quartil & $100 \%$ & $51 \%$ & $100 \%$ \\
2015 & & & \\
1 Quartil & $100 \%$ & $22 \%$ & $100 \%$ \\
2 Quartil & $100 \%$ & $39 \%$ & $100 \%$ \\
3 Quartil & $100 \%$ & $47 \%$ & $100 \%$ \\
\hline
\end{tabular}

Fonte: Resultados da pesquisa
A fronteira invertida poderia ser avaliada tanto na ótica do modelo CCR quanto do modelo BCC. Foi escolhido o modelo $\mathrm{BCC}$ visto que, a partir deste, poderia se avaliar a eficiência técnica, que advém das práticas tomadas pelos administradores e possibilita a sugestão de práticas para estes, e não da eficiência produtiva, calculada pelo modelo CCR.

Confirmando a teoria, todas as cooperativas que obtiveram o escore de $100 \%$ no modelo BCC e o menor escore de todos na fronteira invertida, foi a cooperativa que obteve a eficiência normalizada máxima. As demais, que obtinham valores altos tanto na fronteira padrão $\mathrm{BCC}$ quanto na invertida, se tornavam cooperativas medianas no quesito eficiência normalizada, uma vez que invertendo os valores de insumos e produtos a eficiência era aproximada.

$\mathrm{Na}$ busca por informações que auxiliassem os gestores de cooperativas na tomada de decisão, de forma geral, foi identificado cada cooperativa com eficiência máxima normalizada por ano e porte, identificadas na Tabela 8 . Após essa identificação, foi feita a razão da soma dos inputs utilizados pela soma dos outputs alcançados, obtendo assim um percentual mínimo que os inputs representariam sobre os outputs das cooperativas observadas. Para que a análise não fosse enviesada pelo caráter ambíguo da variável Ativo, visto que essa conta é acumulada ao longo de tempo de vida da instituição e pode ser analisada como input e output, foram feitos dois cálculos: input/output com ativo e input/output sem ativo.

Assim, toma-se como referência que, para as cooperativas denominadas de pequeno porte, o ideal seria que seus inputs, ou seja, o que é gasto com despesas administrativas e de captação para se conseguir os produtos, representassem em média $0,46 \%$ dos outputs, de modo que fosse alcançada a eficiência máxima, no período analisado. Para as cooperativas de médio porte, esse valor deveria representar em média $0,80 \%$ dos outputs totais almejados. E por fim, para cooperativas grandes, esses percentuais deveriam ser de $0,78 \%$. Vale ressaltar que estes índices são válidos para variáveis que coincidam com as usadas neste trabalho e também dado que as cooperativas em análise já tenham certo nível de estruturação.

Ainda, foi feita uma análise dos percentuais, retirando o ativo total da soma dos outputs totais, como supracitado. Não considerando o ativo total dentre as variáveis de saída, observa-se também, na Tabela 8 os novos percentuais, indicando o quanto se deve gastar em recursos para se alcançar uma eficiência normalizada máxima. 
TABELA 8 - Razão entre input/output das cooperativas de crédito de Minas Gerais com máxima eficiência normalizada

\begin{tabular}{|c|c|c|c|}
\hline & & Input/output com ativo & Input/output sem ativo \\
\hline 1 Quartil & Cooperativa & & \\
\hline 2013 & CECM Teksid Brasil & $0,49 \%$ & $4,10 \%$ \\
\hline 2014 & CECM Teksid Brasil & $0,48 \%$ & $4,33 \%$ \\
\hline 2015 & CECM Teksid Brasil & $0,41 \%$ & $3,69 \%$ \\
\hline Média & & $0,46 \%$ & $4,04 \%$ \\
\hline \multicolumn{4}{|l|}{2 Quartil } \\
\hline 2013 & CCLA do Carmo do Paranaíba & $0,85 \%$ & $5,62 \%$ \\
\hline 2014 & CCLA de Campos Altos LTDA & $0,56 \%$ & $5,01 \%$ \\
\hline 2015 & CCLA do Carmo do Paranaíba & $0,99 \%$ & $5,93 \%$ \\
\hline Média & & $\mathbf{0 , 8 0 \%}$ & $5,52 \%$ \\
\hline \multicolumn{4}{|l|}{3 Quartil } \\
\hline 2013 & CCLA da Região do Alto Paranaíba & $0,31 \%$ & $3,65 \%$ \\
\hline 2014 & CCLA do Triângulo Mineiro & $0,87 \%$ & $6,49 \%$ \\
\hline 2015 & CCLA Sudoeste MG e Nordeste SP & $1,16 \%$ & $10,31 \%$ \\
\hline Média & & $0,78 \%$ & $6,82 \%$ \\
\hline
\end{tabular}

Fonte: Resultados da pesquisa

Nota: CECM, Cooperativa de Economia e Crédito Mútuo; CCLA, Cooperativa de Crédito de Livre Admissão

Para as cooperativas de pequeno porte, é necessário que os insumos utilizados totalizem no máximo $4,04 \%$ do montante de sobras mais operações de crédito do período analisado. Para cooperativas de médio porte, este percentual se limita a $5,52 \%$ e para as que são classificadas como de grande porte, no máximo $6,82 \%$. Estes índices mostram qual o nível máximo de gastos - despesas administrativas e com captação - em relação ao crédito concedido e as sobras geradas, uma cooperativa para ser eficiente deve manter, conforme esse modelo e nesse período de tempo analisado. Pode ser uma referência, para os anos seguintes, supondo que o comportamento passado irá se repetir no futuro. Ressaltando novamente que deve ser levado em consideração caso sejam avaliadas outras variáveis em outros estudos.

\section{CONSIDERAÇÕES FINAIS}

O objetivo geral deste trabalho foi analisar a eficiência das pequenas, médias e grandes cooperativas de crédito do estado de Minas Gerais. Utilizou-se para tal a metodologia DEA, que forneceu esses escores de eficiência e permitiu a análise dos dados encontrados. A amostra foi composta por 161 das 198 cooperativas de crédito do estado.
Com relação aos dados estatísticos do estudo, as médias encontradas nos escores das cooperativas de pequeno porte foram semelhantes, com aproximadamente $86,3 \%$ de eficiência nos 3 anos referente ao modelo BCC, indicando que as demais cooperativas desse grupo, as quais não estão no nível de eficiência máxima, podem aumentar em $13,7 \%$ os seus resultados sem ampliar os seus gastos. O índice de possível melhoramento neste aspecto para as médias e grandes cooperativas foram de $23 \%$ e $19 \%$, respectivamente.

Em relação ao porte das cooperativas, ao se fazer o cálculo da média geral de eficiência dos três modelos, notou-se que as cooperativas de médio porte possuem maior potencial para se adquirir eficiência. A quantidade de pequenas cooperativas eficientes era de $33 \%$, de médias $40 \%$ e de grandes cooperativas 30,4\%. Estas informações são das cooperativas que obtiveram escores de eficiência entre $90 \%$ e $100 \%$, aqui consideradas eficientes.

Quanto a média total dos escores encontrados nos três modelos, as cooperativas médias também foram as que tiveram melhor desempenho. Com base nisso, as cooperativas de pequeno, médio e grande porte obtiveram médias dos escores gerais de eficiência de $68,5 \%, 77 \%$ e $71 \%$, respectivamente. Isso indica que as demais cooperativas de cada porte, as quais não estão no nível de eficiência máxima, podem aumentar em $31,5 \%, 23 \%$ e $29 \%$ o nível 
de operações de crédito, sobras e ativo total sem ampliar suas despesas administrativas e de capitação.

Pode-se observar também que as cooperativas apresentam maior eficiência de escala do que técnica, ou seja, há uma boa organização no que diz respeito a sua capacidade operacional, porém ainda falta o que se aprimorar nas decisões tomadas pelos gestores para a otimização de recursos.

Analisando a relação do ativo total das cooperativas, observa-se um aumento com o passar dos anos, fato constatado na divisão dos quartis. Contudo, não se pode dizer que o aumento do ativo das cooperativas contribuiu para o aumento de eficiência das mesmas, uma vez que os escores de eficiência anuais não apresentam tendência crescente ao longo dos anos. As cooperativas, independente do porte, aumentaram seus bens, mas não necessariamente este fato implicou em eficiência.

Foram encontradas as cooperativas de referência quanto à eficiência dentre os quartis e os anos analisados. Como colocado, todas as cooperativas que obtiveram em seu determinado quartil e ano o escore mais alto na fronteira padrão e o mais baixo na fronteira invertida, se tornou a maior referência entre elas, uma vez que a subtração de 1 no escore de fronteira invertida representa a eficiência padrão.

Como recomendação de práticas bem-sucedidas para gestores de cooperativas, obteve-se os percentuais de quanto era necessário se gastar em insumos para se alcançar determinado nível de produtos. Assim, pode-se concluir que utilizando como inputs despesas com captação e despesas administrativas, e como outputs sobras ou perdas e operações de crédito, tem-se que o montante investido não pode ultrapassar $4,04 \%$ do total almejado para cooperativas pequenas, $5,52 \%$ e $6,82 \%$ para médias e grandes cooperativas, respectivamente.

Observa-se que o nível de despesas gastas para o alcance de operações e sobras das cooperativas de médio porte são muito aproximados, dando margem também para se assumir a sua semelhança operacional, ou seja, que as cooperativas de médio porte trabalham mais aproximadas de sua capacidade máxima. Assim, elas estão com maior eficiência em relação aos outros portes.

Por fim, notou-se que independente dos modelos utilizados para o cálculo de eficiência das cooperativas, todos demonstram que ainda há muito o que se aprender ao se gerenciar essas organizações. Como limitação deste estudo pode ser considerado o fato de não ter sido avaliado aspectos espaciais, visando identificar se estes, dada a diversidade econômica e social no estado de
Minas Gerais, contribuem para os níveis de eficiência das cooperativas de crédito estudadas. Sugere-se para estudos posteriores que sejam analisadas práticas individuais de cada cooperativa que é denominada eficiente. A partir desta análise será possível inferir com precisão a respeito das práticas que levam os melhores resultados, dado determinado porte.

\section{REFERÊNCIAS}

ANGULO-MEZA, L., BIONDI NETO, L., SOARES de MELLO, J. C. C. B., GOMES, E. G. ISYDS - Integrated System for Decision Support (SIAD - Sistema Integrado de Apoio a Decisão): A Software Package for Data Envelopment Analysis Model. Pesquisa Operacional, Rio de Janeiro, n. 25, p. 493-503, set./dez. 2005. Disponível em: <http://www.scielo.br/pdf/pope/v25n3/27835.pdf $>$. Acesso em: 24 de junho de 2016.

ANTONIALLI, L. M. Modelo de gestão e estratégias: o caso de duas cooperativas de leite e café de Minas Gerais. São Paulo, 2000. 238 f. Tese (Doutorado em Administração) - Faculdade de Economia, Administração e Contabilidade, Universidade de São Paulo.

APERGiS, N., \& ALEVIZOPOULOU, E. Bank efficiency: Evidence from a panel of European banks. Panoeconomicus, 58(3), 329-341. 2011.

ASSAF NETO, A. Estrutura e análise de balanços: um enfoque econômico financeiro. $5^{\text {a }}$ ed. São Paulo: Atlas, 2000.

BACEN - Banco Central do Brasil. Cooperativas de crédito e seus impactos sociais.2006. Disponível Em $<$ http://www.bcb.gov.br/pre/microFinancas/arquivos/ horario_arquivos/trab_50.pdf $>$. Acesso em $17 \mathrm{de}$ mar. 2016.

BACEN - Banco Central do Brasil. Relatório de atividades da Diretoria de Fiscalização 1995-2002. Disponível em: <http://www.bcb.gov.br/ftp/defis/ RelAtiv8/capitulos_3_e_4.pdf $>$. Acesso em: 18 mar. 2016.

BELlONI, J. A. Uma Metodologia de avaliação da eficiência produtiva de Universidade Federais Brasileiras. 2000. Tese (Doutorado em Engenharia da Produção). Universidade Federal de Santa Catarina, Florianópolis, 2000. 
BIALOKSORSKI NETO, S. Economia das organizações cooperativas: uma análise da influência da cultura e das instituições. 2004. 178 f. Tese (Livre do cência) Faculdade de Economia, Administração e Contabilidade de Ribeirão Preto, Universidade de São Paulo, Ribeirão Preto, 2004.

BIALOSKORSKI NETO, S. Um ensaio sobre desempenho econômico e participação em cooperativas agropecuárias. Rev. Econ. Sociol. Rural [online]. 2007, vol.45, n.1 [cited 2016-05-03], pp.119-138. Disponível em: $<$ http://www.scielo.br/scielo.php?script $=$ sci arttext\&pid=S0103-20032007000100006\&lng=en\&nrm =iso $>$. Acesso em 03 de Maio de 2016.

BITTENCOURT, G. A. Abrindo a caixa preta - O financiamento da agricultura familiar do Brasil. Dissertação de Mestrado - Campinas - SP. 2003.

BORGES, R. C. Dependência espacial da eficiência econômico-financeira: Um estudo em cooperativas de crédito de livre admissão, 2015. Tese (doutorado) - Universidade Federal de Lavras. Lavras: UFLA, 2015.

BRANCH, B.; BAKER, C.; CHAPTER. Overcoming Credit Union Governance Problems. IN WESTLEY, G. D., BRANCH, B. (org.). Safe money: building effective credit unions in Latin America. Washington: Inter-American Development Bank and World Council of Credit Unions, 2000.

BRESSAN, V. G. F. et al. Avaliação de insolvência em cooperativas de crédito: uma aplicação do sistema Pearls. RAM, Rev. Adm. Mackenzie (Online), São Paulo, v. 12, n. 2, p. 113-144, 2011 . Disponível em $<$ http://www.scielo.br/scielo.php?script=sci_arttext\&pid $=$ S1678-69712011000200006\&lng=pt\&nrm=iso $>$. Acesso em 19 mar. 2016.

CHARNES A.; COOPER W.W; LEWIN A.Y.; SEIFORD, L. Data Envelopment Analysis: theory, methodology and applications. EUA: Kluwer Academic Publishers,. 1994.

CHAVES, A. Expansão das microfinanças e desenvolvimento local: oportunidades para o cooperativismo de crédito e instituições de microcrédito. Recife, 09 jun. 2006. Disponível em:<http://www.bcb.gov.br/pre/ SeMicro5/Palestras/12_1_Alessandro.pdf $>$. Acesso em: 24 de março de 2016.
CUEVAS, C. E., FISCHER, K. p. Cooperative financial institutions: issues in governance, regulation, and supervision. Washington: The World Bank, 2006.

FERREIRA, M. A. M.; GONCALVES, R. M. L.; BRAGA, M. J. Investigação do desempenho das cooperativas de crédito de Minas Gerais por meio da Análise Envoltória de Dados (DEA). Econ. Apl., Ribeirão Preto, v. 11, n. 3, p. 425-445, set. 2007 .Disponível em $<$ http://www.scielo.br/scielo.php?script=sci_arttext\&pid $=$ S1413-80502007000300006\&lng=pt\&nrm=iso $>$. Acesso em 19 mar. 2016.

HÖHER, Ricardo; DE SOUZA, Osmar Tomaz; FOCHEZATTO, Adelar. Análise da eficiência: um estudo nas cooperativas financeiras do Rio Grande do Sul. Revista de Gestão e Organizações Cooperativas, [S.1.], v. 6, n. 11, p. 257-276, jul. 2019. ISSN 2359-0432. Disponível em: <https://periodicos.ufsm.br/rgc/article/ view/35988>. Acesso em: 29 jan. 2020. doi:http://dx.doi. org/10.5902/2359043235988.

MEZA, Lidia Angulo; BIONDI NETO, Luiz; MELLO, João Carlos Correia Baptista Soares de and GOMES, Eliane Gonçalves. ISYDS- Integrated System for Decision Support (SIAD - Sistema Integrado de Apoio a Decisão): a software package for data envelopment analysis model. Pesqui. Oper. 2005, vol.25, n.3, pp.493-503. Available from: <http://www. scielo.br/scielo.php?script $=$ sci_arttext\&pid=S0101$74382005000300011 \& \operatorname{lng}=\mathrm{en} \& n \mathrm{~nm}=\mathrm{iso}>$.Acesso em 12 de julho de 2016.

NAKAGAWA, M. Estudo de alguns aspectos de controladoria que contribuem para a eficácia gerencial. Tese de doutorado, Faculdade de Economia, Administração e Contabilidade, Universidade do Estado de São Paulo, São Paulo, SP, Brasil. (1987).

NEVES JÚNIOR, I. J. D.; MOREIRA, S. A.; VASCONCELOS, E. D. S.; BRITO, J. L. Análise da eficiência na geração de retorno aos acionistas das empresas do setor da construção civil com ações negociadas na BM\&FBOVESPA nos anos de 2009 e 2010 por meio da análise envoltória de dados. Revista Contemporânea de Contabilidade, v. 9, n. 18, p. 41-62, 2012. 
PUIG-JUNOY, J. Eficiencia enlaatención primaria de salud: una revisión crítica de las medidas de frontera. Rev. Esp. Salud Publica. 2000, vol.74, n.5-6, pp. 00-00 . Disponível em: <http://www. scielosp.org/scielo.php?script $=$ sci_arttext\&pid $=\mathrm{S} 1135$ $57272000000500005 \& \operatorname{lng}=$ pt\&nrm $=$ iso $>$. Acesso em 02 de Maio de 2016.

SCHARDONG, A. Cooperativa de Crédito: Instrumento de Organização Econômica da Sociedade. Porto Alegre: Rigel, 2002. Sindicato e Organização das Cooperativas do Estado de Minas Gerais. 2016. Disponível em $<$ http://minasgerais.coop.br/Repositorio/Publicacoes/ anuario_2015/index.html\#16/z>. Acesso em 16 de maio de 2016.
SOUZA, U. R. de; BRAGA, M. J.e FERREIRA, M. M. Fatores associados à eficiência técnica e de escala das cooperativas agropecuárias paranaenses.Rev. Econ. Sociol. Rural [online]. 2011, vol.49, n.3, pp.573-597. Disponível em: $<$ http://www.scielo.br/scielo.php?script $=$ sci arttext\&pid $=$ S0103-20032011000300003\&lng =en\&nrm $=\overline{\mathrm{i}}$ so>. Acesso em 01 de janeiro de 2016.

VILELA, D. L.; NAGANO, M. S.; MERLO, E. M. Aplicação da análise envoltória de dados em cooperativas de crédito rural. Rev. adm. Contemp. 2007, vol.11, n.spe2 [citado 2016-04-11], pp.99-120. Disponível em: <http://www.scielo.br/scielo.php?script=sci arttext\&pid=S1415-65552007000600006\&lng=en\&nrm =iso>. Acesso em 11 de abril de 2016. 